\title{
The vicious cycle: a history of obesity and COVID-19
}

\author{
Jacek Bil ${ }^{1^{*}}$ (1) and Olga Możeńska²
}

\begin{abstract}
Recently, we face a surge in the fast-forward Coronavirus Disease 2019 (COVID-19) pandemic with nearly 170 million confirmed cases and almost 3.5 million confirmed deaths at the end of May 2021. Obesity, also known as the pandemic of the 21 st century, has been evolving as an adverse prognostic marker. Obesity is associated with a higher risk of being SARS-CoV-2-positive (46\%), as well as hospitalization (113\%) and death (48\%) due to COVID-19. It is especially true for subjects with morbid obesity. Also, observational studies suggest that in the case of COVID-19, no favorable "obesity paradox" is observed. Therefore, it is postulated to introduce a new entity, i.e., coronavirus disease-related cardiometabolic syndrome (CIRCS). In theory, it applies to all stages of COVID-19, i.e., prevention, acute proceedings (from COVID-19 diagnosis to resolution or three months), and long-term outcomes. Consequently, lifestyle changes, glycemic control, and regulation of the renin-angiotensin-aldosterone pathway have crucial implications for preventing and managing subjects with COVID-19. Finally, it is crucial to use cardioprotective drugs such as angiotensinconverting enzyme inhibitors/angiotensin II receptor blockers and statins. Nevertheless, there is the need to conduct prospective studies and registries better to evaluate the issue of obesity in COVID-19 patients.
\end{abstract}

Keywords: Coronavirus disease-related cardiometabolic syndrome, Statins, SARS-CoV-2, High-processed food, ACE2, GLP-1

\section{Background}

Recently, we face a surge in the fast-forward Coronavirus Disease 2019 (COVID-19) pandemic with nearly 170 million confirmed cases and almost 3.5 million confirmed deaths at the end of May 2021 [1]. Recently, in BMC Cardiovascular Disorders, several interesting papers have been published focusing on risk factors of severe prognosis and COVID-19 complications.

Li et al. analyzed data of 100 subjects with a severe type of COVID-19 [2]. The multivariable analysis found that male sex (HR 5.09, 95\% CI 1.19-22.17) and hypertension (HR 9.88, 95\% CI 2.52-28.70) were the risk factors

\footnotetext{
*Correspondence: biljacek@gmail.com

${ }^{1}$ Department of Invasive Cardiology, Centre of Postgraduate Medical Education, Woloska Street 137, 02-507 Warsaw, Poland

Full list of author information is available at the end of the article

This article belongs to the Topical Collection: Primary Prevention and Cardiovascular Risk.
}

of cardiac injury. The cardiac injury was observed in $25 \%$ of cases, and the mortality was $4.0 \%$. Unfortunately, the authors did not assess the role and impact of obesity in the COVID-19 course. Sardu et al. evaluated the effect of $\mathrm{ABO}$ blood groups on outcomes in patients with hypertension and COVID-19 [3]. Blood group other than O was associated with a higher risk of cardiac injury (HR 2.57, 95\% CI 1.21-5.49) and death (HR 3.71, 95\% CI 1.22-11.24). And finally, Silverio et al., in a large metaanalysis (45 studies, over 18,000 subjects), showed that only diabetes was related to in-hospital mortality in subjects with COVID-19 [4].

However, during COVID-19, another critical factor has emerged, i.e., obesity, defined as body mass index over $30.0 \mathrm{~kg} / \mathrm{m}^{2}$. Obesity, also known as the pandemic of the 21st century, has evolved as a prognostic marker of worse outcomes. Unfortunately, home isolation, home office, and sedentarism during the COVID-19 pandemic 
intensify the problem of overweight and obesity-the perfect vicious cycle [5]. Indeed, in large-scale studies, even over $30 \%$ of respondents confirmed weight gain during the lockdown $(19.5-31.5 \%)$. Moreover, overweight or obese respondents were more likely to report weight gain during the pandemic than respondents with normal body weight [6].

\section{Main text}

\section{Obesity as a negative prognostic marker}

Popkin et al., in a recent huge meta-analysis (75 studies, 399,461 patients from Asia, Europe, North America, and South America), proved that subjects with obesity were at a higher risk of being SARS-CoV-2-positive (OR 1.46, 95\% CI 1.30-1.65) as well as had a higher risk of complications in the COVID-19 course (hospitalization-OR 2.13, 95\% CI 1.74-2.60; intensive care unit admissionOR 1.74, 95\% CI 1.46-2.08; and in-hospital death-OR 1.48, 95\% CI 1.22-1.80) [7]. The most recent studies focusing on COVID-19 course and obesity are provided in Table 1 [8-12]. In some of these studies, obesity was defined as BMI $>28 \mathrm{~kg} / \mathrm{m}^{2}$ (especially in the Asian population) [8], and in some, the significant impact of COVID-19 was observed only in subjects with morbid obesity with BMI $40-45 \mathrm{~kg} / \mathrm{m}^{2}[10,12]$.

Interestingly, this was confirmed in a meta-analysis of 76 studies with 17,860,001 subjects. This meta-analysis showed that the worse prognosis of COVID-19 was observed in subjects over 75 years of age, males, and severe obesity (OR 2.57, 95\% CI 1.31-5.05) [13]. Also, data from HOPE COVID-19 Registry did not support the presence of, known from other disease entities, the potentially favorable "obesity paradox" in subjects with COVID-19 [14].

\section{Coronavirus disease-related cardiometabolic syndrome}

However, the question persists why obese subjects are at risk for severe COVID-19 course? Obesity per se is a metabolic entity characterized by systemic metabolism changes, such as insulin resistance, increased serum glucose, a high leptin/adiponectin ratio, and a persistent low-grade inflammatory state [15]. Obesity is a key player in classical cardiometabolic syndrome. Moreover, vascular and lung function alterations, impaired immune response, and viral-bacterial interactions may play a significant role (Fig. 1) [16].

Sarver et al. proved diet- and gender-dependent changes in angiotensin-converting enzyme 2 (ACE2) expression in the trachea and lungs [15]. ACE2 expression was increased in the lungs and trachea of dietinduced obese male mice comparing with lean subjects. Also, in diet-induced obese mice, males characterized more pronounced ACE2 expression in the trachea than females. And ACE2 upregulation may predispose to SARS-CoV-2 infection. Consequently, fatty tissue in subjects with obesity may behave as a milieu for more intense SARS-CoV-2 replication. The large volume of adipose tissue (especially in males) may promote accelerated viral shedding and exaggerated immune response leading to severe complications $[18,19]$.

Therefore, it is postulated to introduce a new entity, i.e., coronavirus disease-related cardiometabolic syndrome (CIRCS) [20]. It applies to all stages of COVID-19, including its prevention, acute proceedings (from COVID-19 diagnosis to resolution or three months), and long-term outcomes. Components of acute CIRCS include abnormal adiposity, cardiovascular diseases, acute kidney injury, severe acute respiratory syndrome, high insensible water losses, and hypernatremia, encephalopathy, hypercoagulable state, and thromboembolism as well as metabolic disturbances (hypercytokinemia, inflammatory

Table 1 Obesity as a risk factor for the worse COVID-19 course

\begin{tabular}{|c|c|c|c|c|c|}
\hline Study & Patients & $\begin{array}{l}\text { Hospitalization } \\
\text { OR }(95 \% \mathrm{CI})\end{array}$ & $\begin{array}{l}\text { ICU admission } \\
\text { OR }(95 \% \mathrm{Cl})\end{array}$ & $\begin{array}{l}\text { In-hospital death } \\
\text { OR }(95 \% \mathrm{CI})\end{array}$ & $\begin{array}{l}\text { Severe course } \\
\text { OR }(95 \% \mathrm{CI})\end{array}$ \\
\hline Popkin [7] & 399,461 & $2.13(1.74-2.60)$ & $1.74(1.46-2.08)$ & $1.48(1.22-1.80)$ & - \\
\hline Cai [8] & 383 & - & - & - & $3.40(1.40-2.86)$ \\
\hline Simonnet [9] & 124 & - & $7.36(1.63-33.14)^{a}$ & - & - \\
\hline Petrilli [10] ${ }^{b}$ & 5,279 & - & - & $1.45(0.99-2.13)$ & $1.71(1.10-2.7)$ \\
\hline Yates [11] & 54,254 & - & $\begin{array}{l}3.91(3.13-4.88) \\
5.03(3.94-6.63)^{\mathrm{a}}\end{array}$ & $1.93(1.49-2.51)$ & - \\
\hline Kompaniyets [12] & 148,494 & $1.33(1.30-1.37)$ & $\begin{array}{l}1.16(1.11-1.20) \\
2.08(1.89-2.29)^{\mathrm{a}}\end{array}$ & $1.61(1.47-1.76)$ & - \\
\hline
\end{tabular}

$O R$ odds ratio, $C l$ confidence interva, $I C U$ intensive care unit

${ }^{a}$ Requiring invasive mechanical ventilation

${ }^{\mathrm{b}} \mathrm{BMI}>40 \mathrm{~kg} / \mathrm{m}^{2}$ 


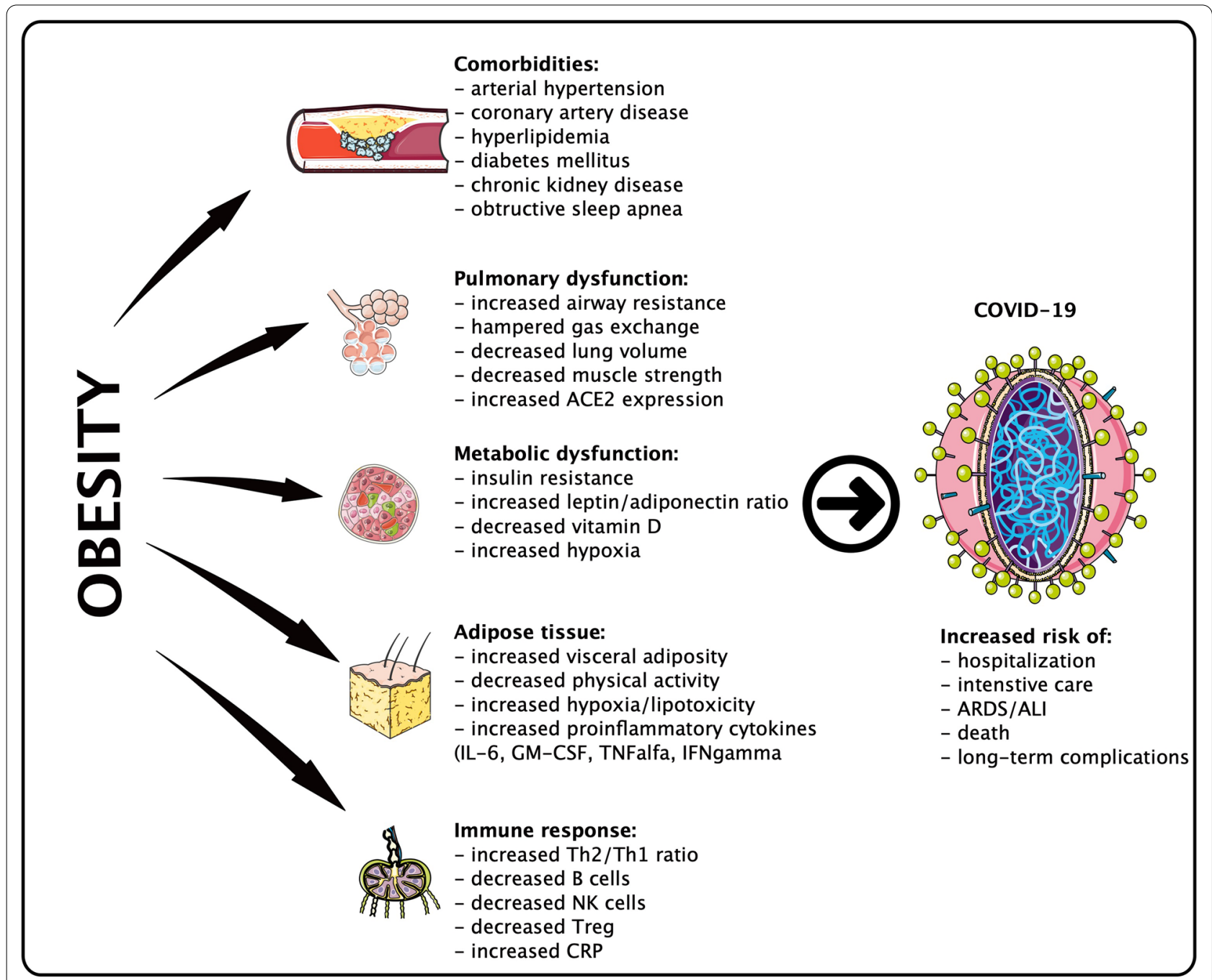

Fig. 1 The influence of obesity on the severe course of COVID-19. ACE2 angiotensin converting enzyme 2, ALl acute lung injury, ARDS acute respiratory distress syndrome, CRP C-reactive protein, GM-CSF granulocyte-macrophage colony stimulating factor, IFNgamma interferon gamma, IL-6 interleukin 6, TNFalfa tumor necrosis factor alfa

state, severe insulin resistance, hyperglycemia, hyperphosphatemia, and hypocalcemia). Such subjects are at high risk of the unfavorable COVID-19 course, and therefore, we should aggressively manage crucial metabolic risk factors of cardiovascular disorders in COVID19 subjects (especially those with obesity) [20].

\section{Pharmacotherapy options to improve outcome in obese COVID-19 subjects}

One of the crucial elements is the renin-angiotensinaldosterone pathway. Angiotensin II receptor type 1 (AT-1) blockade by angiotensin II receptor blockers (ARB) or inhibition of angiotensin II formation by ACE inhibitors, frequently administered in obese subjects with arterial hypertension and diabetes mellitus, may theoretically predispose to an increase in transmembrane ACE2 levels with a simultaneous decrease in soluble ACE2 levels. Nevertheless, there is a broad agreement amid professional medical societies in Europe and America to carry on with renin-angiotensin-aldosterone pathway inhibitors in subjects currently taking these medications. Zhang et al. proved that subjects treated with ACE inhibitors/ARB characterized a 63\% lower risk of COVID-19 death than subjects who did not receive ACE inhibitors/ARB [21].

Statins are emerging as another group of drugs that could reduce the risk of unfavorable outcomes in subjects with COVID-19. Kow et al., in a metaanalysis, revealed a significantly decreased risk of a fatal or severe course of COVID-19 in subjects taking 
statins (HR 0.70, 95\% CI 0.53-0.94) [22]. Interestingly, there is an ongoing randomized trial, Ruxo-Sim-20, assessing ruxolitinib (JAK1 and JAK2 kinase inhibitor) administered with simvastatin on viral entry and decrease in inflammation in subjects with COVID-19 (NCT04348695).

Also, glucagon-like-1 receptor agonists (GLP-1RAs) may play an important role in obese patients with COVID-19. These drugs have been initially used in diabetes treatment but now are also used in the management of obesity itself. GLP-1RAs exhibit anti-inflammatory properties, exert pulmonary protective effects, and have a beneficial influence on, gut microbiome [23]. However, in some animal studies, GLP-1RAs increased ACE-2 levels promoting SARS-CoV-2 infection [24]. Therefore, further well-conducted clinical studies are still in need.

\section{When one pandemic propels the other}

Unfortunately, we observed negative consequences with lockdown and home isolation. De Luis et al. showed an increase in self-reported body weight in obese subjects. It was mainly associated with eating snacks (subgroup eating snacks: $2.60 \pm 0.36$ vs. subgroup not eating snacks: $1.30 \pm 0.17 \mathrm{~kg}, \mathrm{p}<0.01)$ in only a 7 -week observation [25]. Nowadays, during the COVID-19 pandemic, the rapid upsurge in consumption of high-processed food and decreased energy expenditure in pretty all countries regardless of the income will probably rev up the incidence of overweight, obesity, and other non-communicable diseases in the foreseeable future.

\section{Conclusions}

The cumulative incidence of overweight/obese subjects and the elderly is a crucial problem worldwide. Subjects with overweight and obesity outface a higher risk of detrimental COVID-19 complications, like hospitalization, intensive care management, and death. This is especially true for subjects with morbid obesity. Also, observational studies suggest that in the case of COVID-19, no favorable "obesity paradox" is observed. Inflammatory state, a hallmark of aging and obesity, may play a crucial role in promoting an unfavorable COVID-19 course. Lifestyle, glycemic control, and regulation of the renin-angiotensin-aldosterone pathway have important implications for preventing and managing subjects with COVID-19. And it is crucial to use cardioprotective drugs such as ACE inhibitors/ARB and statins. Nevertheless, there is the need to conduct prospective studies and registries better to evaluate the issue of obesity in COVID-19 patients.

\section{Abbreviations}

ACE2: Angiotensin-converting enzyme 2; AT-1: Angiotensin II receptor type 1; CIRCS: Coronavirus disease-related cardiometabolic syndrome; COVID-19:
Coronavirus Disease 2019; HR: Hazard ratio; OR: Odds ratio; SARS-CoV-2: Severe acute respiratory syndrome coronavirus 2.

\section{Acknowledgements}

None.

\section{Authors' contributions}

$\mathrm{JB}$ and $\mathrm{OM}$ have contributed to the literature search, and results interpretation. $\mathrm{JB}$ and $\mathrm{OM}$ have read and approved the final manuscript.

\section{Funding}

Not applicable.

Availability of data and materials

Not applicable.

\section{Declarations}

Ethics approval and consent to participate

Not applicable.

\section{Consent for publication}

Not applicable.

\section{Competing interests}

The authors declare that they have no competing interests.

\section{Author details}

'Department of Invasive Cardiology, Centre of Postgraduate Medical Education, Woloska Street 137, 02-507 Warsaw, Poland. ${ }^{2}$ Department of Internal Medicine, Hypertension and Angiology, Independent Public Central Clinical Hospital, Medical University of Warsaw, Warsaw, Poland.

Received: 2 December 2020 Accepted: 23 June 2021

Published online: 06 July 2021

\section{References}

1. WHO. https://www.who.int/emergencies/diseases/novel-coronavirus2019 (2020). Accessed 27 Nov 2020.

2. Li J, Zhang Y, Wang F, et al. Cardiac damage in patients with the severe type of coronavirus disease 2019 (COVID-19). BMC Cardiovasc Disord. 2020;20(1):479.

3. Sardu C, Marfella R, Maggi P, et al. Implications of ABO blood group in hypertensive patients with covid-19. BMC Cardiovasc Disord. 2020;20(1):373.

4. Silverio A, Di Maio M, Citro R, et al. Cardiovascular risk factors and mortality in hospitalized patients with COVID-19: systematic review and meta-analysis of 45 studies and 18,300 patients. BMC Cardiovasc Disord. 2021;21(1):23.

5. Post A, Bakker SJL, Dullaart RPF. Obesity, adipokines and COVID-19. Eur J Clin Investig. 2020;50:e13313.

6. Pearl RL, Schulte EM. Weight bias during the COVID-19 pandemic. Curr Obes Rep. 2021;10(2):181-190.

7. Popkin BM, Du S, Green WD, et al. Individuals with obesity and COVID-19: a global perspective on the epidemiology and biological relationships. Obes Rev. 2020;21(11):e13128.

8. Cai Q, Chen F, Wang T, et al. Obesity and COVID-19 severity in a designated hospital in Shenzhen, China. Diabetes Care. 2020;43(7):1392-8.

9. Simonnet A, Chetboun M, Poissy J, et al. High prevalence of obesity in Severe Acute Respiratory Syndrome Coronavirus-2 (SARS-CoV-2) requiring invasive mechanical ventilation. Obesity (Silver Spring). 2020;28(7):1195-9.

10. Petrilli CM, Jones SA, Yang J, et al. Factors associated with hospital admission and critical illness among 5279 people with coronavirus disease 2019 in New York City: prospective cohort study. BMJ. 2020;369(m1966.

11. Yates T, Zaccardi F, Islam N, et al. Obesity, ethnicity and risk of critical care, mechanical ventilation and mortality in patients admitted to hospital 
with COVID-19: analysis of the ISARIC CCP-UK cohort. Obesity (Silver Spring). 2021;29(7):1223-30.

12. Kompaniyets $L$, Goodman AB, Belay B, et al. Body Mass Index and risk for COVID-19-related hospitalization, intensive care unit admission, invasive mechanical ventilation, and death - United States, March-December 2020. MMWR Morb Mortal Wkly Rep. 2021;70(10):355-61.

13. Booth $A$, Reed $A B$, Ponzo $S$, et al. Population risk factors for severe disease and mortality in COVID-19: a global systematic review and meta-analysis. PLOS ONE. 2021;16(3):e0247461.

14. Abumayyaleh M, Nunez Gil IJ, El-Battrawy I, et al. Does there exist an obesity paradox in COVID-19? Insights of the international HOPE-COVID19-registry. Obes Res Clin Pract. 2021;15(3):275-80.

15. Landecho MF, Marin-Oto M, Recalde-Zamacona B, Bilbao I, Fruhbeck $\mathrm{G}$. Obesity as an adipose tissue dysfunction disease and a risk factor for infections-Covid-19 as a case study. Eur J Intern Med. 2021;50953-6205(21)00097-2.

16. Guzik TJ, Mohiddin SA, Dimarco A, et al. COVID-19 and the cardiovascular system: implications for risk assessment, diagnosis, and treatment options. Cardiovasc Res. 2020;1 16(10):1666-87.

17. Sarver DC, Wong GW. Obesity alters Ace2 and Tmprss2 expression in lung, trachea, and esophagus in a sex-dependent manner: implications for COVID-19. Biochem Biophys Res Commun. 2020;538:92-96.

18. Shah H, Khan MSH, Dhurandhar NV, Hegde V. The triumvirate: why hypertension, obesity, and diabetes are risk factors for adverse effects in patients with COVID-19. Acta Diabetol. 2021;58(7):831-43.

19. Mahase E. Covid-19: Why are age and obesity risk factors for serious disease? BMJ. 2020:371:m4130.
20. Mechanick Jl, Rosenson RS, Pinney SP, et al. Coronavirus and cardiometabolic syndrome: JACC focus seminar. J Am Coll Cardiol. 2020;76(17):2024-35.

21. Zhang P, Zhu L, Cai J, et al. Association of inpatient use of angiotensinconverting enzyme inhibitors and Angiotensin II receptor blockers with mortality among patients with hypertension hospitalized with COVID-19. Circ Res. 2020;126(12):1671-81.

22. Kow CS, Hasan SS. Meta-analysis of effect of statins in patients with COVID-19. Am J Cardiol. 2020;134:153-5.

23. Belancic A, Kresovic A, Troskot Dijan M. Glucagon-like peptide-1 receptor agonists in the era of COVID-19: friend or foe? Clin Obes. 2021;11(2):e12439.

24. Fandino J, Vaz AA, Toba L, et al. Liraglutide enhances the activity of the ACE-2/Ang(1-7)/Mas receptor pathway in lungs of male pups from foodrestricted mothers and prevents the reduction of SP-A. Int J Endocrinol. 2018;2018:6920620.

25. de Luis Roman DA, Izaola O, Primo Martin D, et al. Effect of lockdown for COVID-19 on self-reported body weight gain in a sample of obese patients. Nutr Hosp. 2020;37(6):1232-37.

\section{Publisher's Note}

Springer Nature remains neutral with regard to jurisdictional claims in published maps and institutional affiliations.
Ready to submit your research? Choose BMC and benefit from:

- fast, convenient online submission

- thorough peer review by experienced researchers in your field

- rapid publication on acceptance

- support for research data, including large and complex data types

- gold Open Access which fosters wider collaboration and increased citations

- maximum visibility for your research: over $100 \mathrm{M}$ website views per year

At BMC, research is always in progress.

Learn more biomedcentral.com/submissions 